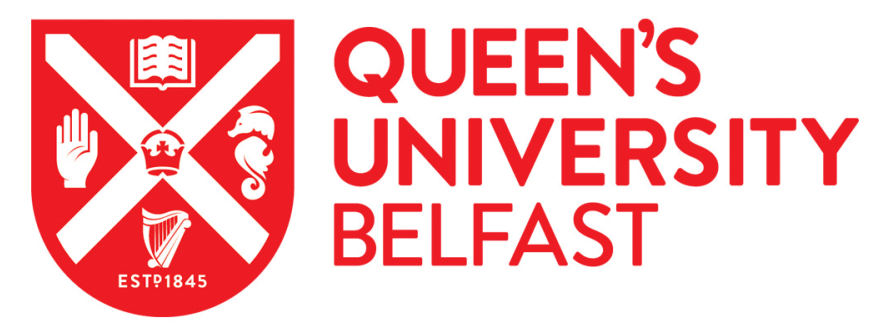

\title{
Walking Exercise for Chronic Musculoskeletal Pain: Systematic Review and Meta-Analysis
}

\author{
O'Connor, S. R., Tully, M. A., Ryan, B., Bleakley, C. M., Baxter, G. D., Bradley, J. M., \& McDonough, S. M. \\ (2015). Walking Exercise for Chronic Musculoskeletal Pain: Systematic Review and Meta-Analysis. Archives of \\ Physical Medicine and Rehabilitation, 96(4), 724-734. https://doi.org/10.1016/j.apmr.2014.12.003
}

\section{Published in:}

Archives of Physical Medicine and Rehabilitation

\section{Document Version:}

Peer reviewed version

\section{Queen's University Belfast - Research Portal:}

Link to publication record in Queen's University Belfast Research Portal

\author{
Publisher rights \\ (c) 2014 Elsevier. \\ This is the author's version of a work that was accepted for publication in Archives of Physical Medicine and Rehabilitation. Changes \\ resulting from the publishing process, such as peer review, editing, corrections, structural formatting, and other quality control mechanisms \\ may not be reflected in this document. Changes may have been made to this work since it was submitted for publication. A definitive version \\ was subsequently published in Archives of Physical Medicine and Rehabilitation, [VOL 96, ISSUE 1, (April 2015)] \\ doi:10.1016/j.apmr.2014.12.003

\section{General rights} \\ Copyright for the publications made accessible via the Queen's University Belfast Research Portal is retained by the author(s) and / or other \\ copyright owners and it is a condition of accessing these publications that users recognise and abide by the legal requirements associated
} with these rights.

Take down policy

The Research Portal is Queen's institutional repository that provides access to Queen's research output. Every effort has been made to ensure that content in the Research Portal does not infringe any person's rights, or applicable UK laws. If you discover content in the Research Portal that you believe breaches copyright or violates any law, please contact openaccess@qub.ac.uk. 


\section{Accepted Manuscript}

Walking Exercise for Chronic Musculoskeletal Pain: Systematic Review and MetaAnalysis

Seán R. O'Connor, PhD, Mark A. Tully, PhD, Brigid Ryan, BSc (Hons), Chris

M. Bleakley, PhD, George D. Baxter, MPhil, Judy M. Bradley, PhD, Suzanne M. McDonough, PhD

PII: S0003-9993(14)01314-8

DOI: 10.1016/j.apmr.2014.12.003

Reference: $\quad$ YAPMR 56061

To appear in: ARCHIVES OF PHYSICAL MEDICINE AND REHABILITATION

Received Date: 21 August 2014

Revised Date: 27 November 2014

Accepted Date: 8 December 2014

Please cite this article as: O'Connor SR, Tully MA, Ryan B, Bleakley CM, Baxter GD, Bradley JM, McDonough SM, Walking Exercise for Chronic Musculoskeletal Pain: Systematic Review and MetaAnalysis, ARCHIVES OF PHYSICAL MEDICINE AND REHABILITATION (2015), doi: 10.1016/ j.apmr.2014.12.003.

This is a PDF file of an unedited manuscript that has been accepted for publication. As a service to our customers we are providing this early version of the manuscript. The manuscript will undergo copyediting, typesetting, and review of the resulting proof before it is published in its final form. Please note that during the production process errors may be discovered which could affect the content, and all legal disclaimers that apply to the journal pertain. 


\section{Title: Walking Exercise for Chronic Musculoskeletal Pain:}

\section{Systematic Review and Meta-Analysis}

Seán R O'Connor PhD ${ }^{1,2,5}$, Mark A Tully PhD ${ }^{1,2}$, Brigid Ryan BSc (Hons) ${ }^{3}$, Chris M Bleakley $\mathrm{PhD}^{4}$, George D Baxter MPhil ${ }^{3}$, Judy M Bradley $\mathrm{PhD}^{5}$, Suzanne M McDonough $\mathrm{PhD}$ *2,5

${ }^{1}$ Centre for Public Health, Queens' University Belfast, United Kingdom

${ }^{2}$ UKCRC Centre of Excellence for Public Health (Northern Ireland), United Kingdom

${ }^{3}$ Centre for Physiotherapy Research, University of Otago, New Zealand

${ }^{4}$ Sport and Exercise Sciences Research Institute, University of Ulster, United Kingdom

${ }^{5}$ Institute of Nursing and Health Research, University of Ulster, United Kingdom

\section{Acknowledgment of financial support}

This study was funded by a PhD award from the Department of Employment and Learning, Northern Ireland, UK

\section{Conflicts of interest}

None declared

* Corresponding author:

Professor Suzanne M McDonough, Room 01F118, School of Health Sciences, University of Ulster, Shore Road, Newtownabbey, Co. Antrim, BT37 0QB, United Kingdom e-mail: s.mcdonough@ulster.ac.uk; Telephone: 00442890366459 


\section{Walking for Musculoskeletal Pain: Review}

\section{ABSTRACT}

3 Objective: To systematically review the evidence examining effects of walking

4 interventions on pain and self-reported function in individuals with chronic

5 musculoskeletal pain.

6 Data Sources: Six electronic databases (Medline, CINAHL, PsychINFO, PEDro, Sport

7 Discus and the Cochrane Central Register of Controlled Trials) were searched from

$8 \quad$ January 1980 up to March 2014.

9 Study Selection: Randomized and quasi-randomized controlled trials in adults with

10 chronic low back pain, osteoarthritis or fibromyalgia comparing walking interventions to

11 a non-exercise or non-walking exercise control group.

12 Data Extraction: Data were independently extracted using a standardized form.

13 Methodological quality was assessed using the United States Preventative Services

14 Task Force (USPSTF) system.

15 Data Synthesis: Twenty-six studies (2384 participants) were included and suitable

16 data from 17 were pooled for meta-analysis with a random effects model used to

17 calculate between group mean differences and 95\% confidence intervals. Data were

18 analyzed according to length of follow-up (short-term: $\leq 8$ weeks post randomization;

19 medium-term: >2 months - 12 months; long-term: > 12 months). Interventions were

20 associated with small to moderate improvements in pain at short (mean difference

21 (MD) $-5.31,95 \%$ confidence interval $(95 \% \mathrm{Cl})-8.06$ to -2.56$)$ and medium-term follow-

22 up (MD -7.92, 95\% Cl -12.37 to -3.48). Improvements in function were observed at

23 short (MD $-6.47,95 \% \mathrm{Cl}-12.00$ to -0.95$)$, medium (MD $-9.31,95 \% \mathrm{Cl}-14.00$ to -4.61 )

24 and long-term follow-up (MD -5.22, 95\% Cl 7.21 to -3.23 ). 


\section{Walking for Musculoskeletal Pain: Review}

25 Conclusions: Evidence of fair methodological quality suggests that walking is

26 associated with significant improvements in outcome compared to control interventions

27 but longer-term effectiveness is uncertain. Using the USPSTF system, walking can be

28 recommended as an effective form of exercise or activity for individuals with chronic

29 musculoskeletal pain but should be supplemented with strategies aimed at maintaining

30 participation. Further work is also required examining effects on important health

31 related outcomes in this population in robustly designed studies.

32

33 Key words: Meta-analysis, walking, exercise, chronic musculoskeletal pain.

34

35

36

37

38

39

40

41

42

43

44

45

46

47

48

49 


\section{Walking for Musculoskeletal Pain: Review}

50 Chronic musculoskeletal pain (CMP) is a major cause of morbidity.(1) Given the

51 changing age profile of the population it is probable that its prevalence and associated

52 costs will continue to rise. $(1,2)$ Chronic low back pain (CLBP), osteoarthritis (OA) and

53 fibromyalgia syndrome (FMS) are reported as being among the most common types of

54 musculoskeletal disorder. These conditions may be associated with significant

55 functional limitations.(2) There is also evidence that they can exert a substantial

56 influence on long-term health status and overall quality of life. $(1,3)$

58 Current treatment recommendations support various non-pharmacological

59 interventions, including aerobic exercise, in order to reduce pain and maintain or

60 increase functional status.(4-6) However, randomized controlled trials have tended to

61 report only short-term improvements in outcome with relatively small effect sizes. $(7,8)$

62 This may be due to a number of factors, including heterogeneity of interventions.(9)

64 Walking may represent an ideal form of aerobic activity, due to its ease of accessibility

65 and relatively low impact. It has a low risk of musculoskeletal injury,(10) and is

66 considered safe to recommend for previously sedentary individuals.(11) Low to

67 moderate intensity walking (described as exercising at a MET value of between 3-4

68 (12) or a pace that results in an increased respiratory and heart rate, but where the

69 individual can still carry out a conversation) has been shown to lead to improvements

70 in aerobic capacity, body mass index, systolic/diastolic blood pressures, triglyceride,

71 and high density lipoprotein cholesterol levels in healthy sedentary individuals, $(13,14)$

72 as well as in those with established cardiovascular disease (15) and type 2

73 diabetes.(16) 


\section{Walking for Musculoskeletal Pain: Review}

74 Although it is widely recommended, there is currently limited evidence relating to the

75 effectiveness of walking exercise for management of musculoskeletal disorders.(17)

77 The aim of this systematic review was to examine the effects of walking interventions

78 on pain and self-reported function in adults with CMP.

80 METHODS

\section{Data sources, searches and extraction}

83 Comprehensive search strategies were carried out by at least two independent

84 reviewers according to the preferred reporting items for systematic reviews and meta-

85 analyses (PRISMA) recommendations and those of the Cochrane Musculoskeletal

86 Review Group. $(18,19)$ A review protocol was developed 'a priori' using the PICOS

87 framework to define the research question and inclusion criteria. Six electronic

88 databases (Medline, CINAHL, PsychINFO, PEDro, Sport Discus and the Cochrane

89 Central Register of Controlled Trials) were searched for relevant papers published

90 between January 1980 and March 2014 using combinations of key terms which

91 included "walking", "aerobic exercise”, "musculoskeletal pain”, "low back pain”,

92 "arthritis" and "fibromyalgia" (A full list of the MeSH terms used is included in

93 Supplementary data: Appendix A). Reference lists of included articles and key

94 systematic reviews were also checked by hand.

96 All randomized or quasi-randomized studies published in full were considered for

97 inclusion. No language restrictions were applied. Studies were required to include 


\section{Walking for Musculoskeletal Pain: Review}

98 adults aged 18 years or over, with a diagnosis of CLBP, OA or FMS made according to

99 clinical judgement or accepted diagnostic criteria. $(6,20,21)$

100

101 All land or treadmill based walking interventions were considered for inclusion. Studies

102 were required to include a comparative non-exercise or non-walking exercise control

103 group. Those including any form of assisted walking were excluded. Studies were also

104 excluded if they involved peri-operative or post-operative interventions. Primary

105 outcomes of interest were pain and self-reported function.

107 At least two reviewers independently examined titles and abstracts of identified

108 studies. Full text copies of potentially eligible studies were assessed to determine

109 whether walking formed at least half of the overall intervention. Final inclusion was

110 determined by consensus between review authors. Data were extracted independently

111 using a standardised form. Disagreements were resolved by consensus and involved a

112 third author if required. Intervention and control group sample size, plus mean and

113 standard deviation (SD) values for pain and function were extracted. Where the SD

114 was not provided it was calculated from the standard error (SE) or 95\% confidence

115 intervals $(95 \% \mathrm{Cl})$. Where tabulated results were not presented, an attempt was made

116 to extract data from graphs. All data were cross checked by a second author. For the

117 purposes of comparability, outcomes were converted to a 0-100 scale (with higher

118 scores indicating greater pain or functional limitation).

120 Assessment of methodological quality and adequacy of exercise interventions

121 The United States Preventative Services Task Force (USPSTF) system was used to

122 assess methodological quality and form treatment recommendations based on an 


\section{Walking for Musculoskeletal Pain: Review}

123 estimate of net benefit and the overall strength of evidence.(22) Internal validity and

124 external validity were rated as "good", "fair", or "poor" according to pre-defined criteria

125 specific to the study design.(23) (See supplementary data: Appendix B). Studies rated

126 as "good" met all relevant criteria. Fair studies did not meet all criteria while "poor"

127 studies were judged to contain a serious methodological flaw. Individual studies were

128 given an overall rating, with internal and external validity considered to have equal

129 weighting. Included studies were also screened for statements indicating sources of

130 funding or support. Reviewers were not blinded with regards to study authors,

131 institution, or journal of publication. All final decisions regarding quality assessment

132 and overall recommendations were reached by consensus. Studies were also

133 scrutinized independently to determine if the interventions met American College of

134 Sports Medicine (ACSM) guidelines for the quantity and quality of aerobic exercise in

135 inactive individuals based on frequency, intensity, timing, mode and duration of

136 interventions.(24)

\section{Data synthesis and analysis}

139 The meta-analysis compared mean values for pain and function between walking

140 intervention and control groups. To avoid double counting, where multiple treatment

141 groups were included walking was compared only to minimal intervention controls.

142 Suitable studies were considered to be clinically homogeneous on the basis of

143 similarities in participant demographics and intervention methods. These data were

144 pooled and analyzed using RevMan (v.5.2.8).(25) Statistical heterogeneity was

145 assessed using the $\chi^{2}$ and $I^{2}$ test statistics. Where the $P$ value was less than 0.05 or

146 the $I^{2}$ value greater than $50 \%$, indicating large heterogeneity,(26) a random effects

147 model for inverse variance was used to calculate the mean difference and $95 \% \mathrm{Cl}$. 


\section{Walking for Musculoskeletal Pain: Review}

148 Formal statistical tests were not used to assess publication bias, which was evaluated

149 using visual assessment of funnel plots. Data were analyzed by length of follow-up

150 which was categorized as short ( $\leq 8$ weeks post randomization), medium (2-12 months)

151 or long-term (>12 months). Sensitivity analyses were carried out excluding studies

152 where walking was combined with a co-intervention.

154 Nine articles were not included in the meta-analysis for the following reasons: no

155 validated self-reported measure of pain or function $(27,28)$ (one study used a

156 functional scale that contained additional questions related to global health status and

157 these data were therefore not included); unadjusted baseline differences between

158 groups; $(29,30)$ presented median data only; $(31,32)$ change over time only $(33)$ or did

159 not include a measure of variability.(34) One study reported pain as an outcome but

160 did not include these data in the paper.(35)

161

162 RESULTS

163

164 Description of studies

165 The electronic database searches revealed a total of 2760 articles after exclusion of

166 duplicates. Thirty seven of these met the inclusion criteria (see Appendix C for a list of

167 excluded studies). Eleven were reports of follow-up data or sub-sample analyses.

168 There were therefore 26 original studies in the review including a total of 2384

169 participants (Mean: 93) with an average age of 57 years (SD: 15 ), of whom $77 \%$ were

170 female. The complete selection process, including reasons for exclusion is shown in

171 Figure 1.

172 


\section{Walking for Musculoskeletal Pain: Review}

173 Twenty four of the studies were randomized controlled trials. Twelve provided data for

174 OA $(27-29,31,36-43)$, eight for FMS $(30,33-35,44-47)$, five for CLBP $(32,48-51)$ and

175 one included participants with chronic hip, lower back or knee pain.(52) Demographic

176 details and study characteristics are summarized in Table 1 and Table 2.

178 In the majority of interventions (19/26, 73\%) walking was supervised in a hospital

179 clinic, gymnasium or other setting (Table 2). Some studies combined supervised

180 walking with instructions to walk at home;(31,37,40) six were home-based

181 only. $(28,30,32,38,43,51)$ Three used pedometers to assist with step-based walking

182 goals $(28,43,51)$ while three used time-based walking goals. $(30,32,38)$

184 Thirteen studies included a walking only intervention group. The remaining combined

185 walking with a co-intervention. The most common of which were educational

186 interventions or alternative forms of exercise (Table 2). A range of controls were used

187 including education; usual care; alternative forms of exercise; a passive intervention

188 (relaxation/massage) and a 6-8 week pre-intervention baseline phase. Mean length of

189 final follow-up was 1.8 months (SD: 0.4$)$ for studies with short term outcomes $(\leq 8$

190 weeks post randomization); 4.9 months (SD: 1.9) for medium-term outcomes (>2-12

191 months); and 18.4 months (SD: 7.6) for long-term outcomes (>12 months).

193 Eleven studies included a statement of associated adverse events. These included two

194 falls resulting in distal radial fractures, one fall resulting in a hip fracture, one case of

195 plantar fasciitis and two cases of allergic skin reactions to metal pedometer clips. Two

196 studies including participants with fibromyalgia reported a general increase in reporting

197 of pain and muscle stiffness in the intervention group. One study including participants 


\section{Walking for Musculoskeletal Pain: Review}

198 with CLBP reported temporary exacerbations in pain levels in a small number of

199 participants which was attributed to unaccustomed activity levels.

\section{Methodological quality and exercise interventions}

202 Overall, the included evidence was judged to be of at least fair methodological quality

203 (Supplementary data: Appendix B). Six studies met all criteria for internal validity and

204 were rated as good. $(32,33,37,47,48,51)$ A small number of studies $(n=5)$ contained

205 serious potential sources of methodological bias and were therefore rated as

206 poor. $(27,28,30,31,43)$ This was as a result of inadequate allocation concealment

207 during randomization, $(28,30)$ unequal distribution of important confounding variables at

208 baseline not accounted for during analysis, $(27,30)$ no masking of outcome

209 assessment,(31) or due to a substantial (>50\%) drop-out rate and subsequent post

210 hoc revision of the intervention groups examined.(29) For external validity most studies

211 were rated as fair, with nine rated as good. $(32,33,36,38,42,43,47,50,51)$ Studies

212 generally included similar populations in terms of demographics and clinical

213 presentation, as well as interventions that would be routinely available or feasible in

214 clinical practice. Visual assessment of funnel plots indicated that there was no

215 substantial evidence of publication bias. Only one study (27) did not include a

216 statement indicating sources of funding or support. Ten studies $(35-37,40,41,44-$

$21746,49,50)$ included interventions that met all ACSM criteria.(24) (Supplementary data:

218 Appendix B) While the majority met minimum criteria for frequency of exercise and

219 length of intervention, eleven either did not provide enough detail regarding exercise

220 intensity, or it was not sufficient to effect any change in fitness. Eleven of the 26

221 studies $(32,33,36,37,39,40,41,43,47,51,52)$ reported a measure of participant

222 adherence (Table 2). These included attendance at exercise classes $(n=7)$, self- 


\section{Walking for Musculoskeletal Pain: Review}

223 reported completion of home exercise $(n=2)$ or self-reported adherence to wearing a 224 pedometer $(n=2)$. 


\section{Walking for Musculoskeletal Pain: Review}

225

226

227

228

229

230

231

232

233

234

235

236

237 results.

\section{DISCUSSION}

241 Overall findings indicated that walking interventions were associated with significant

242 improvements in both pain and self-reported function in individuals with CMP. While

243 effects appeared to be maintained beyond the immediate post-intervention period, only

244 differences in function were observed at long-term follow-up. This was based primarily

245 on data derived from interventions lasting for between six and 12 months. It is

246 therefore unlikely that improvements in outcome would be maintained following the

247 shorter intervention periods included in the majority of other interventions. This is

248 supported by additional sub-sample data from one included study which indicated that 


\section{Walking for Musculoskeletal Pain: Review}

249 significant improvements in outcome following an eight week intervention were absent

250 at 12 months.(53)

251

252 While it has been suggested that supervised interventions may be required to maintain

253 adherence with exercise,(7) other techniques, including those encouraging self-

254 management, may be of benefit.(54) Walking did appear to have a slightly greater

255 effect on function than pain outcomes. Inclusion of educational and behavioral

256 components alongside walking in many studies may have contributed to this apparent

257 effect; lending support to treatment approaches which place greater emphasis on

258 improving function despite continued pain.(55) These interventions are often based on

259 psychological theories such as operant conditioning which use positive reinforcement

260 to reduce negative pain behaviors; for example through graded activity or pacing.(56)

261 The underlying mechanisms contributing to these effects are uncertain but could be

262 related to reduced fear of movement or increased self-efficacy.(55) Although co-

263 interventions varied, there were commonalities: including that they frequently consisted

264 of hospital or clinic-based group discussions (supplemented with written information),

265 with condition-specific and general information on pain management strategies and

266 advice on maintaining exercise. Some studies included additional strategies including

267 goal setting and self-monitoring. Use of self-monitoring techniques including

268 pedometer feedback represents a potentially useful method to increase walking in

269 individuals with CMP disorders. $(43,51)$ However, these methods have not been widely

270 tested. This is reflected in the fact that only three of the included studies used

271 pedometers. A recent study examining a remote, web-delivered pedometer

272 intervention (excluded from this review as it compared two forms of walking) found no 


\section{Walking for Musculoskeletal Pain: Review}

273 long-term effects on functional outcomes.(57) Further work is required examining

274 pedometer interventions in this population which are delivered within a clinical setting.

276 To our knowledge, this is one of the first systematic reviews to examine the effects of

277 walking in a range of CMP disorders. A previous review (58) examining walking for

278 LBP (both acute and chronic) found limited evidence to support its use as a primary

279 intervention. Roddy and co-authors (59) found aerobic walking to be equally as

280 effective as strengthening at reducing pain and disability in knee OA. Other reviews

281 examining the effects of general aerobic exercise interventions in $\operatorname{CMP}(7,8,60,61)$

282 have provided conflicting results, with limited evidence to support the use of any one

283 type or intensity of exercise. While aerobic exercise may lead to improved overall well-

284 being and physical function it is often associated with little or no difference in

285 pain. $(60,62)$ In contrast, others have shown slight to moderate intensity aerobic

286 exercise to be effective at reducing pain;(8) however this latter review did not look

287 directly at effects on functional data.

289 Study strengths and limitations

290 This review has a number of strengths, including an extensive search of the available

291 evidence, rather than limiting inclusion to studies selected on the basis of experimental

292 design. We also included studies which involved only walking-based interventions,

293 allowing for examination of a more homogenous intervention type than has previously

294 been examined. Studies were considered to be similar on the basis of clinical

295 characteristics and intervention methods. The majority involved supervised treadmill or

296 land-based interventions (commonly within a hospital or clinic gymnasium setting), of

297 between six to eight weeks duration. A number of these studies included more 


\section{Walking for Musculoskeletal Pain: Review}

298 independent home-based walking as an additional exercise element and we were

299 therefore unable to determine the influence of treatment setting on outcomes.

301 We were unable to use sensitivity analysis to examine studies separately on the basis

302 of quality as only one study included in the meta-analysis contained a potential serious

303 methodological flaw which could have compromised its validity. Use of the USPSTF

304 system allowed a qualitative assessment of the overall evidence to be made, and the

305 findings and conclusions were broadly similar between this assessment method and

306 the results of the meta-analysis.

308 There are some limitations which should be taken into account when considering these

309 findings. A small number of studies had methodological limitations, including

310 inadequate allocation concealment in randomized controlled trials or lack of an

311 appropriate method for dealing with missing data. In six studies there was insufficient

312 information on masking of outcome assessments and with additional information it is

313 possible that some studies rated as "fair" may have been rated as "poor" which would

314 influence the recommendation made on the basis of the evidence included in the

315 review. Many studies lacked sufficient detail to assess adequacy of the exercise

316 interventions. The overall effects of the interventions may also have been attenuated

317 by the small number of non-intervention control groups. Furthermore, few studies

318 reported whether there were any associated adverse events. Even among the more

319 supervised interventions, there was limited detail regarding participant adherence.

320 Further research is required examining interventions which use objective measurement

321 of overall physical activity as both an important outcome and a method for increasing

322 motivation and use of self-monitoring. Objective monitors are more accurate than 


\section{Walking for Musculoskeletal Pain: Review}

323 subjective assessment methods, due to recall and social-desirability biases of

324 subjective reports (63). Objective monitors such as pedometers can give immediate

325 feedback on performance (prompting adherence), however, one limitation is that they

326 require the user to remember to put them on. Other solutions, such as wrist worn,

327 waterproof devices, that don't need to be removed for sleep or water based activities

328 may offer a solution, but may not provide the same quality of visual feedback that a

329 pedometer does. Such issues should be considered in the design of future research.

$331 \quad$ Conclusions

332 Meta-analysis of data from studies of at least fair methodological quality demonstrated

333 that walking may lead to improvements in outcome, comparable to other forms of

334 exercise. Using the USPSTF system to summarize the existing evidence, walking-

335 based exercise can be recommended for individuals with CMP. However, robustly

336 designed research is required examining longer-term maintenance of walking

337 programs and their effects on important health related outcomes in this population.

\section{AUTHOR CONTRIBUTIONS}

344 All authors contributed to the conception and design of this review. SOC, BR, CB and

345 SMcD were responsible for conducting the search strategies and extracting study data.

346 SOC, MT, GDB, JB and SMcD were responsible for assessment of study quality and

347 rating the overall strength of evidence. SOC drafted the manuscript and all authors

348 contributed to and approved the finalised version. 


\section{Walking for Musculoskeletal Pain: Review}

\section{References}

351 1. Vos $T$, Flaxman AD, Naghavi M, et al. Years lived with disability (YLDs) for 1160

352 sequelae of 289 diseases and injuries 1990-2010: a systematic analysis for the Global

353 Burden of Disease Study 2010. Lancet 2012;380(9859):2163-96.

355 2. Reid KJ, Harker J, Bala MM, et al. Epidemiology of chronic non-cancer pain in

356 Europe: narrative review of prevalence, pain treatments and pain impact. Curr Med 357 Res Opin 2011;27:449-62.

359 3. Landmark T, Romundstad P, Borchgrevink PC, et al. Associations between 360 recreational exercise and chronic pain in the general population: evidence from the 361 HUNT 3 study. Pain 2011;152:2241-7.

363 4. Zhang W, Nuki G, Moskowitz RW, et al. OARSI recommendations for the 364 management of hip and knee osteoarthritis Part III: changes in evidence following 365 systematic cumulative update of research published through January 2009. 366 Osteoarthritis Cartilage 2010;18:476-99.

368 5. The Map of Medicine and the British Pain Society. Chronic Widespread Pain 369 including Fibromyalgia. England view, London, 2013.

371 6. Delitto A, George SZ, Van Dillen L, et al. Low Back Pain: Clinical Practice 372 Guidelines Linked to the International Classification of Functioning, Disability, and 


\section{Walking for Musculoskeletal Pain: Review}

373 Health from the Orthopaedic Section of the American Physical Therapy Association. J

374 Orthop Sports Phys Ther 2012;42(4):A1-A57.

375

376 7. Fransen M, McConnell S. Land-based exercise for osteoarthritis of the knee: a

377 meta-analysis of randomized controlled trials. J Rheumatol 2009;36:1109-17.

379 8. Häuser W, Klose P, Langhorst J, et al. Efficacy of different types of aerobic exercise

380 in fibromyalgia syndrome: a systematic review and meta-analysis of randomised

381 controlled trials. Arthritis Res Ther 2010;12:R79.

382

383 9. Foster NE. Barriers and progress in the treatment of low back pain. BMC Medicine $384 \quad 2011 ; 27 ; 9: 108$.

385 10. Hootman JM, Macera CA, Ainsworth BE, et al. Association among physical activity 386 level, cardiorespiratory fitness, and risk of musculoskeletal injury. Am J Epidemiol $387 \quad 2001 ; 154: 251-8$.

388 11. Colbert LH, Hootman JM, Macera CA. Physical activity-related injuries in walkers 389 and runners in the aerobics center longitudinal study. Clin J Sport Med 2000;10:25939063.

392 12. Ainsworth BE, Haskell WL, Herrmann SD, et al. Compendium of Physical 393 Activities: a second update of codes and MET values. Med Sci Sports 394 Exerc. 2011;43(8):1575-81. 


\section{Walking for Musculoskeletal Pain: Review}

397 13. Tully MA, Cupples ME, Hart ND, et al. Randomised controlled trial of home-based 398 walking programmes at and below current recommended levels of exercise in 399 sedentary adults. J Epidemiol Community Health 2007;61:778-83.

400 14. Tschentscher M, Niederseer D, Niebauer J. Health benefits of nordic walking: a 401 systematic review. Am J Prev Med. 2013 Jan;44(1):76-84.

402 15. Eijsvogels T, George K, Shave R, et al. Effect of prolonged walking on cardiac 403 troponin levels. Am J Cardiol 2010;105:267-72.

405 16. Johnson ST, Bell GJ, McCargar LJ, et al. Improved cardiovascular health following 406 a progressive walking and dietary intervention for type 2 diabetes. Diabetes Obes 407 Metab 2009;11:836-43.

409 17. Mody GM, Brooks PM. Improving musculoskeletal health: global issues. Best Pract 410 Res Clin Rheumatol 2012;26(2):237-49.

412 18. Moher D, Liberati A, Tetzlaff J, et al. PRISMA Group. Preferred reporting items for 413 systematic reviews and meta-analyses: the PRISMA statement. PRISMA Group. Ann 414 Intern Med 2009;151:264-9.

415 19. Maxwell L, Santesso N, Tugwell PS, et al. Method guidelines for Cochrane 416 Musculoskeletal Group systematic reviews. J Rheumatol 2006;33:2304-11.

417 20. Zhang W, Doherty M, Peat G, et al. EULAR evidence-based recommendations for 418 the diagnosis of knee osteoarthritis. Ann Rheum Dis 2010;69:483-9. 


\section{Walking for Musculoskeletal Pain: Review}

420 21. Wolfe F, Clauw DJ, Fitzcharles MA, et al. The American College of Rheumatology

421 preliminary diagnostic criteria for fibromyalgia and measurement of symptom severity.

422 Arthritis Care Res 2010;62:600-10.

423

424 22. Sawaya GF, Guirguis-Blake J, LeFevre M, et al. U.S. Preventive Services Task

425 Force. Update on the methods of the U.S. Preventive Services Task Force: estimating

426 certainty and magnitude of net benefit. Ann Intern Med 2007;147:871-75.

428 23. Harris RP, Helfand M, Woolf, SH, et al. Methods work group, Third US Preventive 429 Services Task Force, 2001. Current methods of the US Preventive Services Task 430 Force: a review of the process. Am J Prev Med, 20(Supplement 3):21-35.

432 24. American College of Sports Medicine. ACSM's Guidelines for Exercise Testing and 433 Prescription. $9^{\text {th }}$ edn. Philadelphia, USA: Lippincott Williams \& Wilkins. 2009.

435 25. Review Manager (RevMan) [Computer program]. Version 5.0. Copenhagen: The 436 Nordic Cochrane Centre, The Cochrane Collaboration, 2008.

438 26. Higgins JPT, Thompson SG, Deeks JJ, et al. Measuring inconsistency in meta439 analyses. BMJ 2003;327:557-60.

441 27. Bautch JC, Clayton MK, Chu Q, et al. Synovial fluid chondroitin sulphate epitopes 442 3B3 and 7D4, and glycosaminoglycan in human knee osteoarthritis after exercise. Ann 443 Rheum Dis 2000;59:887-91. 


\section{Walking for Musculoskeletal Pain: Review}

445 28. Hiyama Y. Yamada M. Kitagawa A, et al. A four-week walking exercise programme

446 in patients with knee osteoarthritis improves the ability of dual-task performance: a

447 randomized controlled trial. Clin Rehabil 2012; 26(5):403-12.

449 29. Bautch JC, Malone DG, Vailas AC. Effects of exercise on knee joints with 450 osteoarthritis: a pilot study of biologic markers. Arthritis Care Res 1997;10:48-55.

452 30. Meyer BB, Lemley KJ. Utilizing exercise to affect the symptomology of 453 fibromyalgia: a pilot study. Med Sci Sports Exerc 2000;32:1691-7.

455 31. Dias RC, Dias JM, Ramos LR. Impact of an exercise and walking protocol on 456 quality of life for elderly people with OA of the knee. Physiother Res Int 2003;8:121457130.

458 32. Rasmussen-Barr E, Ang B, Arvidsson I, et al. Graded Exercise for Recurrent Low459 Back Pain. A Randomized, Controlled Trial With 6-, 12-, and 36-Month Follow-ups. 460 Spine 2009;34:221-228.

461 33. Lemstra M, Olszynski WP. The effectiveness of multidisciplinary rehabilitation in 462 the treatment of fibromyalgia: a randomized controlled trial. Clin J Pain 2005;21:16646374.

465 34. Holtgrefe K, McCloy C, Rome L. Changes associated with a quota-based approach 466 on a walking program for individuals with fibromyalgia. J Orthop Sports Phys Ther $467 \quad 2007 ; 37: 717-24$. 


\section{Walking for Musculoskeletal Pain: Review}

469 35. Martin L, Nutting A, Maclntosh BR, et al. An exercise program in the treatment of

470 fibromyalgia. J Rheumatol 1996;23:1050-3.

471

472 36. Brosseau L, Wells GA, Kenny GP, et al. The implementation of a community-based

473 aerobic walking program for mild to moderate knee osteoarthritis: A knowledge

474 translation randomized controlled trial: Part II: Clinical outcomes. BMC Public Health.

4752012 Dec 12;12(1):1073.

476

477 37. Ettinger WH, Burns R, Messier SP, et al. A randomized trial comparing aerobic 478 exercise and resistance exercise with a health education program in older adults with 479 knee osteoarthritis. The Fitness Arthritis and Seniors Trial (FAST). JAMA 1997;277:2548031.

482 38. Evcik D, Sonel B. Effectiveness of a home-based exercise therapy and walking 483 program on osteoarthritis of the knee. Rheumatol Int 2002;22:103-6.

484 39. Kovar PA, Allegrante JP, MacKenzie CR, et al. Supervised fitness walking in 485 patients with osteoarthritis of the knee. A randomized, controlled trial. Ann Intern Med $486 \quad 1992 ; 116: 529-534$.

487 40. Messier SP, Loeser RF, Miller GD, et al. Exercise and Dietary Weight Loss in 488 Overweight and Obese Older Adults With Knee Osteoarthritis: The Arthritis, Diet, and 489 Activity Promotion Trial. Arthritis Rheum 2004;50:1501-10. 


\section{Walking for Musculoskeletal Pain: Review}

491 41. Miller GD, Nicklas BJ, Davis C, et al. Intensive Weight Loss Program Improves

492 Physical Function in Older Obese Adults with Knee Osteoarthritis. Obesity $493 \quad 2006 ; 14: 1219-30$.

494

495 42. Schlenk EA, Lias JL, Sereika SM, et al. Improving physical activity and function in 496 overweight and obese older adults with osteoarthritis of the knee: a feasibility study.

497 Rehabil Nurs 2011;36(1):32-42.

498

499 43. Talbot LA, Gaines JM, Huynh TN, et al. A Home-Based Pedometer-Driven Walking

500 Program to Increase Physical Activity in Older Adults with Osteoarthritis of the Knee: A

501 Preliminary Study. J Am Geriatr Soc 2003;51:387-92.

502

503 44. Bircan C, Karasel SA, Akgün B, et al. Effects of muscle strengthening versus 504 aerobic exercise program in fibromyalgia. Rheumatol Int 2008;28:527-32.

506 45. Nichols DS, Glenn TM. Effects of aerobic exercise on pain perception, affect, and

507 level of disability in individuals with fibromyalgia. Phys Ther 1994;74:327-32. 508

509 46. Valim V, Oliveira L, Suda A, et al. Aerobic fitness effects in fibromyalgia. J Rheum $510 \quad 2003 ; 30: 1060-9$.

512 47. Rooks DS, Gautam S, Romeling M, et al. Group exercise, education, and 513 combination self-management in women with fibromyalgia: a randomized trial. Arch 514 Intern Med 2007;167:2192-200. 


\section{Walking for Musculoskeletal Pain: Review}

516 48. Hartvigsen J, Morsø L, Bendix T, et al. Supervised and non-supervised Nordic

517 walking in the treatment of chronic low back pain: a single blind randomized clinical

518 trial. BMC Musculoskelet Disord. 2010;10:30.

520 49. Koldaş Doğan S, Sonel Tur B, Kurtaiş $Y$ et al. Comparison of three different

521 approaches in the treatment of chronic low back pain. Clin Rheumatol 2008;27:873-81.

523 50. Shnayderman I, Katz-Leurer M. An aerobic walking programme versus muscle

524 strengthening programme for chronic low back pain: a randomized controlled trial. Clin

525 Rehabil. 2012 Jul 31. [Epub ahead of print]

527 51. McDonough SM, Tully MA, Boyd A, O'Connor SR, Kerr DP, O'Neill SM, Delitto A,

528 Bradbury I, Tudor-Locke C, Baxter GD, Hurley DA. Pedometer-driven walking for 529 chronic low back pain: a feasibility randomized controlled trial. Clin J Pain. $530 \quad 2013 ; 29(11): 972-81$.

532 52. Ferrell BA, Josephson KR, Pollan AM, et al. A randomized trial of walking versus 533 physical methods for chronic pain management. Aging 1997;9:99-105.

535 53. Sullivan T, Allegrante JP, Peterson MG et al. One-year follow up of patients with 536 oteoarthritis of the knee who participated in a program of supervised fitness walking 537 and supportive patient education. Arthritis Care Res 1998;11:228-33. 


\section{Walking for Musculoskeletal Pain: Review}

539 54. Jordan JL, Holden MA, Mason EE, et al. Interventions to improve adherence to

540 exercise for chronic musculoskeletal pain in adults. Cochrane Database Syst Rev

$541 \quad 2010 ; 1: C D 005956$.

542 55. Greaves CJ, Sheppard KE, Abraham C, et al. IMAGE Study Group. Systematic

543 review of reviews of intervention components associated with increased effectiveness

544 in dietary and physical activity interventions. BMC Public Health 2011;11:119.

545 56. Vincent HK, Seay AN, Montero C, et al. Kinesiophobia and fear-avoidance beliefs

546 in overweight older adults with chronic low-back pain: relationship to walking

547 endurance--part II. Am J Phys Med Rehabil. 2013;92(5):439-45.

549 57. Krein SL, Kadri R, Hughes M et al. Pedometer-based internet-mediated

550 intervention for adults with chronic low back pain: randomised controlled trial. J Med

551 Internet Res 2013;15(8)e181.

553 58. Hendrick $P$, Te Wake AM, Tikkisetty AS, et al. The effectiveness of walking as an

554 intervention for low back pain: a systematic review. Eur Spine J 2010;19(10)1613-20.

556 59. Roddy E, Zhang W, Doherty M. Aerobic walking or strengthening exercise for

557 osteoarthritis of the knee? A systematic review. Ann Rheum Dis 2005;64:544-48.

558 60. Busch AJ, Barber KA, Overend TJ, et al. Exercise for treating fibromyalgia

559 syndrome. Cochrane Database Syst Rev 2007; 4: CD003786.

560 61. Brosseau L, MacLeay L, Robinson V, et al. Intensity of exercise for the treatment

561 of osteoarthritis. Cochrane Database Syst Rev 2003;2:CD004259. 


\section{Walking for Musculoskeletal Pain: Review}

563 62. Ribaud A, Tavares I, Viollet E, Julia M, Hérisson C, Dupeyron A. Which physical

564 activities and sports can be recommended to chronic low back pain patients after

565 rehabilitation? Ann Phys Rehabil Med. 2013;56(7-8):576-94.

566

567 63. Westerterp KR. Assessment of physical activity: a critical appraisal. Eur J Appl

568 Physiol. 2009;105:823-828

569

570

571

572

573

574

575

576

577

578

579

580

581

582

583

584

585

586 


\section{Walking for Musculoskeletal Pain: Review}

587 Figure 1. Preferred Reporting Items for Systematic Reviews and Meta-Analyses

588 (PRISMA) flow diagram showing process of selection for systematic review (16) 589

590 Figure 2. Effect of walking on pain (/100) compared to control interventions 591

592 Figure 3. Effect of walking on self-reported function (/100) compared to control 593 interventions 
Walking for Musculoskeletal Pain: Review

594 
Walking for Musculoskeletal Pain: Review

595 
Table 1. Summary of demographic information from individual studies (studies included in the meta-analysis are highlighted in bold)

\begin{tabular}{|c|c|c|c|c|c|c|}
\hline Study & Condition & Diagnostic Criteria & $\begin{array}{l}\text { Duration of } \\
\text { Symptoms } \\
\text { (years) Mean } \\
\text { (SD) }\end{array}$ & $\begin{array}{l}\text { Age (years) } \\
\text { Mean (SD) }\end{array}$ & $\begin{array}{l}\text { Gender } \\
\text { (\% } \\
\text { Female) }\end{array}$ & $\begin{array}{l}\text { Mass (kg) / BMI } \\
\left(\mathrm{Kg} / \mathrm{m}^{2}\right) \\
\text { Mean (SD) }\end{array}$ \\
\hline $\begin{array}{l}\text { Bautch et al, } \\
2000 \text { (27) }\end{array}$ & OA knee & $\begin{array}{l}\text { Clinical diagnosis according to } \\
\text { ACR criteria * }\end{array}$ & - & $69.7(1.9)$ & 66.7 & $-/ 28.6(1.0)$ \\
\hline $\begin{array}{l}\text { Bautch et al, } \\
1997 \text { (29) }\end{array}$ & OA knee & $\begin{array}{l}\text { Clinical diagnosis according to } \\
\text { ACR criteria * }\end{array}$ & - & $69.0(2.3) \neq$ & $72.7 \ddagger$ & - / $28.7(1.2)$ \\
\hline $\begin{array}{l}\text { Bircan et al, } \\
2008(44)\end{array}$ & FM & $\begin{array}{l}\text { Clinical diagnosis according to } \\
\text { ACR criteria } †\end{array}$ & $4.2(4.3)$ & $47.2(9.5)$ & 100 & $-/-$ \\
\hline $\begin{array}{l}\text { Brosseau et al, } \\
2012(36)\end{array}$ & OA knee & $\begin{array}{l}\text { Clinical diagnosis according to } \\
\text { ACR criteria } †\end{array}$ & $10.3(9.3)$ & $63.4(8.6)$ & 68.9 & $\begin{array}{l}82.2(16.6) / 29.8 \\
(5.4)\end{array}$ \\
\hline $\begin{array}{l}\text { Dias et al, } 2003 \\
\text { (31) }\end{array}$ & OA knee & - & - & $75 \S(65-89 \#)$ & 86.4 & $-1-$ \\
\hline $\begin{array}{l}\text { Ettinger et al, } \\
1997(37)\end{array}$ & OA knee & Radiographic evidence & & $68.6(6.1)$ & 70.4 & $-1-$ \\
\hline $\begin{array}{l}\text { Evcik et al, } \\
2002 \text { (38) }\end{array}$ & OA knee & $\begin{array}{l}\text { Clinical and radiographic } \\
\text { assessment using Kellgren \& } \\
\text { Lawrence criteria }\end{array}$ & $8.1(3.3)$ & $56.3(6.5)$ & 68.9 & $-/-$ \\
\hline $\begin{array}{l}\text { Ferrell et al, } \\
1997(52)\end{array}$ & cMSK pain & $\begin{array}{l}\text { Clinical diagnosis of 'stable' } \\
\text { lower extremity / mechanical } \\
\text { LBP (>3 months) }\end{array}$ & - & $73.2(3.7)$ & 21.1 & $-1-$ \\
\hline $\begin{array}{l}\text { Hartvigsen et } \\
\text { al, } 2010 \text { (48) }\end{array}$ & cLBP & Clinical diagnosis & - & $46.7(10.9)$ & 71.6 & $-1-$ \\
\hline $\begin{array}{l}\text { Hiyama et al, } \\
2012 \text { (28) }\end{array}$ & OA knee & Clinical diagnosis & - & $72.8(5.4)$ & 100 & $\begin{array}{l}59.4(6.9) / 23.7 \\
(2.1)\end{array}$ \\
\hline $\begin{array}{l}\text { Holtgrafe et al, } \\
2007 \text { (34) }\end{array}$ & FM & $\begin{array}{l}\text { Clinical diagnosis according to } \\
\text { ACR criteria } †\end{array}$ & $4.3(4.7)$ & $52.3(18.1)$ & 100 & - / $27.9(5.7)$ \\
\hline Koldas Dogan & cLBP & - & $4.5(5.5)$ & $42.1(9.5)$ & 78.2 & $-1-$ \\
\hline
\end{tabular}




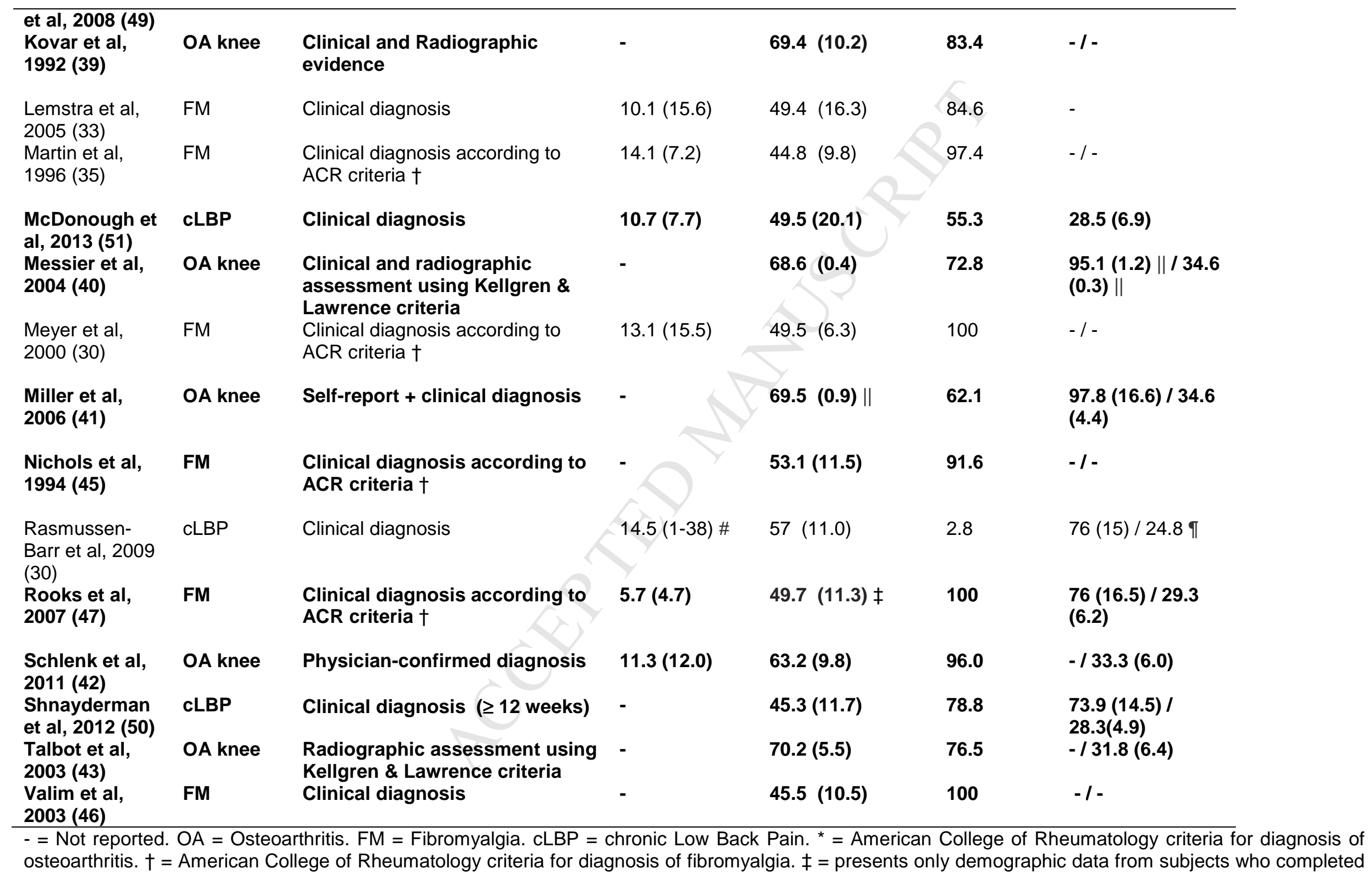


study not total sample. $\S=$ median value. $\|=$ Standard error of mean (SEM). $\boldsymbol{\uparrow}=$ Where not stated in paper value calculated based on mean mass and therefore unable to calculate SD. \# = only range reported. ${ }^{* *}=$ chronic musculoskeletal pain (hip, lower back and knee pain). 
Table 2. Summary of methodological characteristics of individual studies (studies included in the meta-analysis are highlighted in bold)

\begin{tabular}{|c|c|c|c|c|c|c|}
\hline $\begin{array}{l}\text { Study } \\
\text { design \& } \\
\text { blinding }\end{array}$ & $\begin{array}{l}\text { Total } \\
\text { sample }\end{array}$ & Walking group & Control group & $\begin{array}{l}\text { Duration of } \\
\text { intervention } \\
\text { (months) }\end{array}$ & $\begin{array}{l}\text { Reported } \\
\text { adherence } \\
(\%) \dagger\end{array}$ & $\begin{array}{l}\text { Time point of } \\
\text { follow-up } \\
\text { assessment(s) } \\
\text { (post- } \\
\text { randomization): } \\
\text { Drop out; N (\%) }\end{array}$ \\
\hline $\begin{array}{l}\text { Bautch et al, } \\
2000 \text { (27) } \\
\text { RCT/B }\end{array}$ & 30 & Education + treadmill walking & Education & $3 \mathrm{~m}$ & - & $3 \mathrm{~m}: 9(30)$ \\
\hline $\begin{array}{l}\text { Bautch et al, } \\
1997 \text { (29) } \\
\text { RCT/B }\end{array}$ & 34 & Education + treadmill walking & Education & $3 \mathrm{~m}$ & - & $3 \mathrm{~m}: 4$ (11.7) \\
\hline $\begin{array}{l}\text { Bircan et al, } \\
2008(44) \\
\text { RCT/- }\end{array}$ & 30 & Treadmill walking & $\begin{array}{l}\text { General Strengthening } \\
\text { exercise }\end{array}$ & $2 \mathrm{~m}$ & - & $2 \mathrm{m:} 4$ (13.3) \\
\hline $\begin{array}{l}\text { Brosseau et } \\
\text { al, } 2012(36) \\
\text { RCT/B }\end{array}$ & 222 & Supervised walking & Education & $12 \mathrm{~m}$ & 79.0 & $\begin{array}{l}3 \mathrm{~m}: 37(16.6) \\
6 \mathrm{~m}: 19(8.5) \\
9 \mathrm{~m}: 17(7.6) \\
12 \mathrm{~m}: 14(6.3) \\
15 \mathrm{~m}: 5(2.3) \\
18 \mathrm{~m}: 8(3.6)\end{array}$ \\
\hline $\begin{array}{l}\text { Dias et al, } \\
2003(31) \\
\text { RCT/B }\end{array}$ & 50 & $\begin{array}{l}\text { Education + supervised exerci } \\
+ \text { home based walking }\end{array}$ & Education & $1.5 \mathrm{~m}$ & - & $\begin{array}{l}3 \mathrm{~m}:- \\
6 \mathrm{~m}: 3(6)\end{array}$ \\
\hline $\begin{array}{l}\text { Ettinger et } \\
\text { al, } \\
1997(37) \\
\text { RCT/B }\end{array}$ & 439 & $\begin{array}{l}\text { Facility and home based } \\
\text { walking }\end{array}$ & Education & $18 \mathrm{~m}$ & 68.0 & $\begin{array}{l}3 \mathrm{~m}: 47(10.7) \\
9 \mathrm{~m}: 82(18.6) \\
18 \mathrm{~m}: 75(17.1)\end{array}$ \\
\hline $\begin{array}{l}\text { Evcik et al, } \\
2002(38) \\
\text { NRS/- }\end{array}$ & 90 & Home based walking & $\begin{array}{l}\text { Instructed to continue } \\
\text { with normal daily } \\
\text { activities }\end{array}$ & $3 \mathrm{~m}$ & - & 6 m: $9(10)$ \\
\hline
\end{tabular}




\begin{tabular}{|c|c|c|c|c|c|c|}
\hline $\begin{array}{l}\text { Ferrell et al, } \\
1997(52) \\
\text { RCT/- }\end{array}$ & 33 & $\begin{array}{l}\text { Supervised walking on outdoor } \\
\text { track or gymnasium }\end{array}$ & $\begin{array}{l}\text { Pain management } \\
\text { information }\end{array}$ & $1.5 \mathrm{~m}$ & 93.0 & $\begin{array}{l}2 \mathrm{w}:- \\
2 \mathrm{~m}: 4(12.2)\end{array}$ \\
\hline $\begin{array}{l}\text { Hartvigsen } \\
\text { et al, } 2010 \\
\text { (48) RCT/B }\end{array}$ & 136 & Supervised Nordic walking & Education & $2 \mathrm{~m}$ & - & $\begin{array}{l}2 \mathrm{~m}: 10(7.4) \\
6 \mathrm{~m}: 0 \\
12 \mathrm{~m}: 0\end{array}$ \\
\hline $\begin{array}{l}\text { Hiyama et al, } \\
2012(28) \\
\text { RCT/B }\end{array}$ & 40 & $\begin{array}{l}\text { Home based walking (with } \\
\text { pedometer) + ice + general home } \\
\text { exercises }\end{array}$ & $\begin{array}{l}\text { Ice }+ \text { general home } \\
\text { exercises }\end{array}$ & $1 \mathrm{~m}$ & - & $1 \mathrm{~m}: 0$ \\
\hline $\begin{array}{l}\text { Holtgrafe et } \\
\text { al, } 2007 \text { (34) } \\
\text { NRS/B }\end{array}$ & 3 & Hospital based indoor walking & $\begin{array}{l}\text { Pre-intervention, } \\
\text { baseline phase }\end{array}$ & $2 m$ & - & $2 \mathrm{~m}:-$ \\
\hline $\begin{array}{l}\text { Koldas } \\
\text { Dogan et al, } \\
2008 \text { (49) }\end{array}$ & 60 & Treadmill based exercise & $\begin{array}{l}\text { General home } \\
\text { exercises }\end{array}$ & $1.5 \mathrm{~m}$ & - & $\begin{array}{l}1.5 \mathrm{~m}: 5(8.3) \\
2.5 \mathrm{~m}: 5(8.3)\end{array}$ \\
\hline $\begin{array}{l}\mathrm{RCT} /- \\
\text { Kovar et al, } \\
1992(39) \\
\mathrm{RCT} / \mathrm{B}\end{array}$ & 102 & $\begin{array}{l}\text { Hospital based supervised } \\
\text { walking + education }\end{array}$ & $\begin{array}{l}\text { Contacted by phone to } \\
\text { discuss nature of daily } \\
\text { activities }\end{array}$ & $2 \mathrm{~m}$ & 87.5 & $2 \mathrm{m:} 10(9.8)$ \\
\hline $\begin{array}{l}\text { Lemstra et } \\
\text { al, } 2005 \text { (33) } \\
\text { RCT/B }\end{array}$ & 79 & $\begin{array}{l}\text { Supervised aerobic exercise }+ \\
\text { massage }+ \text { education }\end{array}$ & Standard care & $1.5 \mathrm{~m}$ & 90.6 & $\begin{array}{l}1.5 \mathrm{~m}: 7(8.8) \\
15 \mathrm{~m}: 8(10.2)\end{array}$ \\
\hline $\begin{array}{l}\text { Martin et al, } \\
1996(35) \\
\text { RCT/B }\end{array}$ & 60 & $\begin{array}{l}\text { Supervised walking + strength } \\
\text { and flexibility training }\end{array}$ & Relaxation sessions & $1.5 \mathrm{~m}$ & - & $1.5 \mathrm{~m}: 20$ (33.3) \\
\hline $\begin{array}{l}\text { McDonough } \\
\text { et al, 2013 } \\
\text { (51) } \\
\text { fRCT/B }\end{array}$ & 56 & $\begin{array}{l}\text { Pedometer based walking + } \\
\text { education }\end{array}$ & Education & $2 \mathrm{~m}$ & 73.0 & $\begin{array}{l}2 \mathrm{m:}: 7(12.5) \\
6 \mathrm{m:}: 8(14.3)\end{array}$ \\
\hline $\begin{array}{l}\text { Messier et } \\
\text { al, } \\
2004(40) \\
\text { RCT/B }\end{array}$ & 316 & $\begin{array}{l}\text { Facility and home based } \\
\text { aerobic + lower limb resistance } \\
\text { training }\end{array}$ & Usual Care & $18 \mathrm{~m}$ & 60.0 & $\begin{array}{l}6 \mathrm{~m}: 41(12.9) \\
18 \mathrm{~m}: 64(20.2)\end{array}$ \\
\hline $\begin{array}{l}\text { Meyer et al, } \\
2000(30) \\
\text { RCT/- }\end{array}$ & 21 & Home based walking & $\begin{array}{l}\text { Instructed to maintain } \\
\text { current activity levels }\end{array}$ & $6 \mathrm{~m}$ & - & $\begin{array}{l}6 \mathrm{~m}:- \\
18 \mathrm{~m}:-(57.2)\end{array}$ \\
\hline
\end{tabular}




\begin{tabular}{|c|c|c|c|c|c|c|}
\hline $\begin{array}{l}\text { Miller et al, } \\
2006 \text { (41) } \\
\text { RCT/- }\end{array}$ & 87 & $\begin{array}{l}\text { Education + facility / home } \\
\text { based lower limb strengthening } \\
\text { + aerobic training }{ }^{*}\end{array}$ & Education & $6 \mathrm{~m}$ & 77.5 & $6 \mathrm{m:} 8(9.1)$ \\
\hline $\begin{array}{l}\text { Nichols et } \\
\text { al, } \\
1994(45) \\
\text { RCT/- }\end{array}$ & 24 & $\begin{array}{l}\text { Supervised indoor walking } \\
\text { program }\end{array}$ & $\begin{array}{l}\text { Instructed to continue } \\
\text { with usual daily } \\
\text { activities }\end{array}$ & $2 \mathrm{~m}$ & & 2 m: 5 (20.8) \\
\hline $\begin{array}{l}\text { Rasmussen- } \\
\text { Barr et al, } \\
2009 \text { (32) } \\
\text { RCT/B }\end{array}$ & 71 & $\begin{array}{l}\text { Instructed to walk each day plus } \\
\text { given general home exercises }\end{array}$ & $\begin{array}{l}\text { Specific stabilization } \\
\text { exercises with bio- } \\
\text { pressure unit }\end{array}$ & $2 \mathrm{~m}$ & 71.0 & $\begin{array}{l}6 \mathrm{~m}: 7(9.8) \\
12 \mathrm{~m}: 10(14.8) \\
36 \mathrm{~m}: 15(21.2)\end{array}$ \\
\hline $\begin{array}{l}\text { Rooks et al, } \\
2007 \text { (47) } \\
\text { RCT/B }\end{array}$ & 207 & $\begin{array}{l}\text { Treadmill walking + flexibility } \\
\text { training }\end{array}$ & Education & $3 \mathrm{~m}$ & 73.0 & $3 \mathrm{~m}: 72(20.2)$ \\
\hline $\begin{array}{l}\text { Schlenk et } \\
\text { al, } 2011 \text { (42) } \\
\text { RCT/B }\end{array}$ & 26 & Fitness walking + Education & $\begin{array}{l}\text { Usual care + } \\
\text { Education }\end{array}$ & $6 \mathrm{~m}$ & - & $\begin{array}{l}6 \mathrm{~m}: 5(19.2) \\
12 \mathrm{~m}: 5(19.2)\end{array}$ \\
\hline $\begin{array}{l}\text { Shnayderm } \\
\text { an et al, } \\
2012(50) \\
\text { RCT/B }\end{array}$ & 52 & Treadmill walking & $\begin{array}{l}\text { General strengthening } \\
\text { exercise }\end{array}$ & $1.5 \mathrm{~m}$ & - & $1.5 \mathrm{m:} 9$ (17.3) \\
\hline $\begin{array}{l}\text { Talbot et al, } \\
2003 \text { (43) } \\
\text { RCT/UB }\end{array}$ & 40 & Pedometer based walking & Education & $3 \mathrm{~m}$ & 76.0 & $\begin{array}{l}3 \mathrm{~m}:- \\
6 \mathrm{~m}: 6(15)\end{array}$ \\
\hline $\begin{array}{l}\text { Valim et al, } \\
2003(46) \\
\text { RCT/B }\end{array}$ & 76 & Supervised walking & $\begin{array}{l}\text { General stretching } \\
\text { exercises }\end{array}$ & $5 \mathrm{~m}$ & - & $\begin{array}{l}2.5 \mathrm{~m}:- \\
5 \mathrm{~m}: 16(21.1)\end{array}$ \\
\hline
\end{tabular}

RCT: Randomized Controlled Trial. fRCT: Feasibility Randomized Controlled Trial. URT: Uncontrolled Randomized Trial. NRS: Non Randomized Study. B: Blinded outcome assessment. U: Unblinded. - = Not reported. * Walking primary mode of aerobic exercise. † Percentage adherence reported as total number of classes attended; self-reported completion of home exercise or self-reported adherence to wearing a pedometer. w: weeks. m: months. 
Figure 1. Preferred Reporting Items for Systematic Reviews and Meta-Analyses

(PRISMA) flow diagram showing process of selection for systematic review (16)

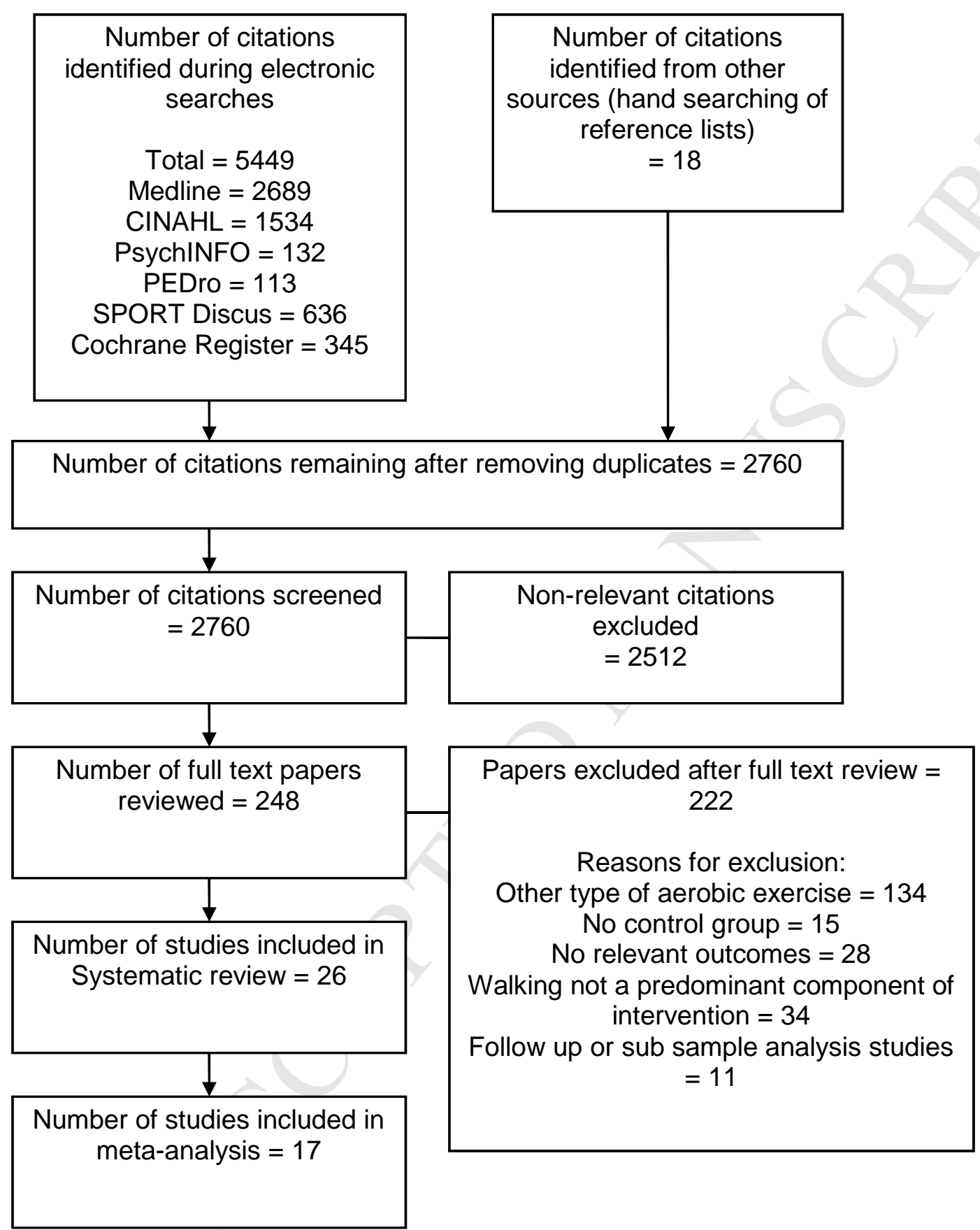


Figure 2. Effect of walking on pain (/100) compared to control interventions

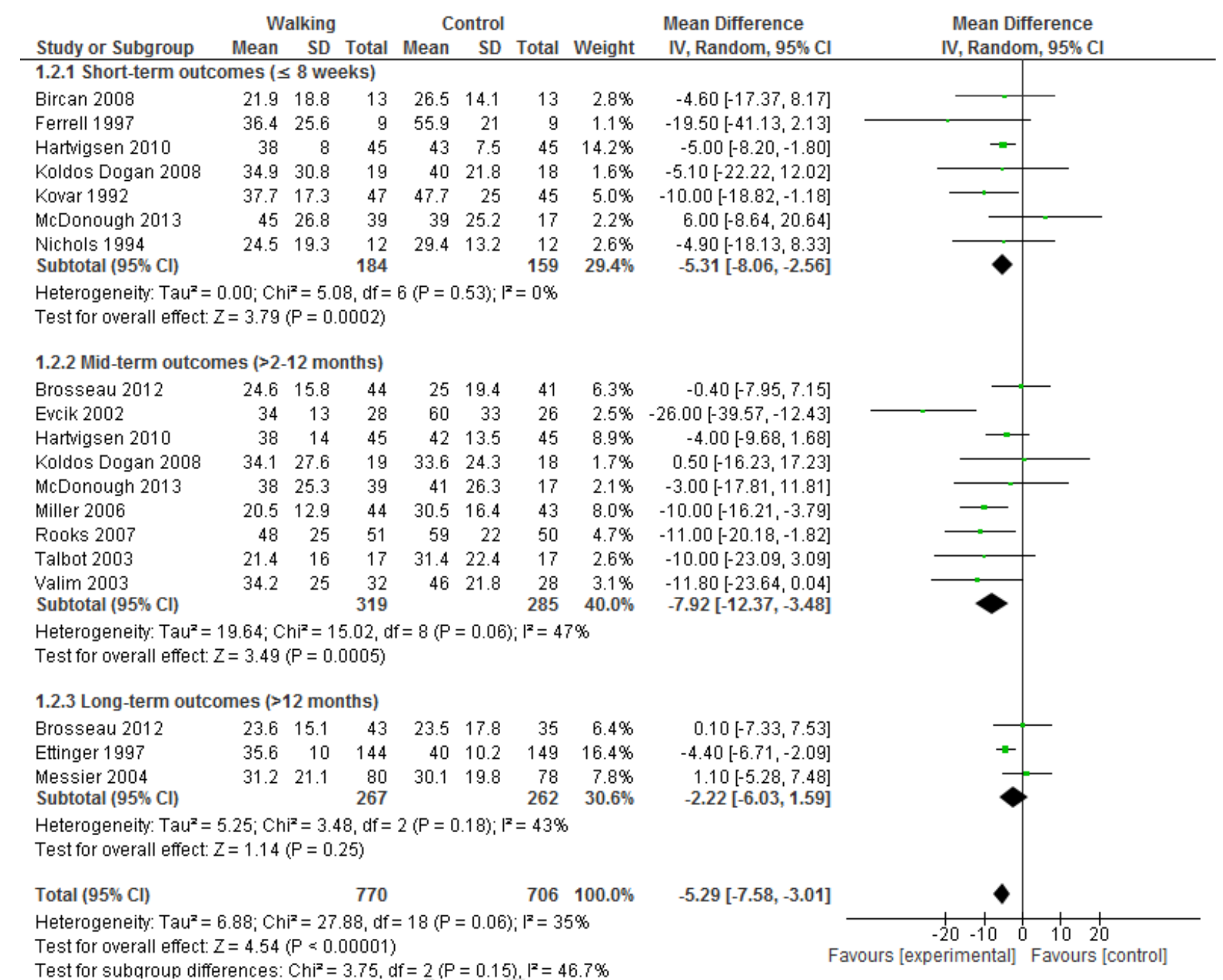




\section{Figure 3. Effect of walking on self-reported function (/100) compared to control interventions}

\begin{tabular}{|c|c|c|c|c|c|c|c|c|c|c|}
\hline \multirow[b]{2}{*}{ Study or Subgroup } & \multicolumn{3}{|c|}{ Walking } & \multicolumn{3}{|c|}{ Control } & \multirow{2}{*}{\multicolumn{2}{|c|}{$\begin{array}{l}\text { Mean Difference } \\
\text { IV, Random, } 95 \% \mathrm{Cl}\end{array}$}} & \multirow{2}{*}{\multicolumn{2}{|c|}{$\begin{array}{l}\text { Mean Difference } \\
\text { IV, Random, } 95 \% \mathrm{Cl}\end{array}$}} \\
\hline & Mean & SD & Total & Mean & SD & Total & & & & \\
\hline \multicolumn{9}{|c|}{ 3.1.1 Short-term outcomes ( $\leq 8$ weeks) } & & \\
\hline Bircan 2008 & 65 & 21.2 & 13 & 69.3 & 18.1 & 13 & $2.8 \%$ & $-4.30[-19.45,10.85]$ & & \\
\hline Ferrell 1997 & 41.5 & 27.5 & 9 & 57 & 16.7 & 9 & $1.7 \%$ & $-15.50[-36.52,5.52]$ & & - \\
\hline Hartvigsen 2010 & 37 & 10.5 & 45 & 45 & 12 & 45 & $8.1 \%$ & $-8.00[-12.66,-3.34]$ & $\rightarrow$ & \\
\hline Koldos Dogan 2008 & 37.1 & 28.3 & 19 & 56.6 & 27.5 & 18 & $2.2 \%$ & $-19.50[-37.48,-1.52]$ & & \\
\hline Kovar 1992 & 33 & 12.1 & 47 & 45.1 & 11.5 & 45 & $8.0 \%$ & $-12.10[-16.92,-7.28]$ & & \\
\hline McDonough 2013 & 26.4 & 17.2 & 39 & 26.8 & 13.5 & 17 & $5.7 \%$ & $-0.40[-8.79,7.99]$ & & \\
\hline Shnayderman 2012 & 22.6 & 14.4 & 26 & 19.1 & 12.8 & 26 & $6.3 \%$ & $3.50[-3.91,10.91]$ & & \\
\hline Subtotal $(95 \% \mathrm{Cl})$ & & & 198 & & & 173 & $34.8 \%$ & $-6.47[-12.00,-0.95]$ & & \\
\hline \multicolumn{11}{|c|}{$\begin{array}{l}\text { Heterogeneity: } \mathrm{Tau}^{2}=30.06 ; \mathrm{Chi}^{2}=17.16, \mathrm{df}=6(\mathrm{P}=0.009) ; \mathrm{I}^{2}=65 \% \\
\text { Test for overall effect: } Z=2.30(\mathrm{P}=0.02)\end{array}$} \\
\hline \multicolumn{11}{|c|}{ 3.1.2 Mid-term outcomes (>2-12 months) } \\
\hline Brosseau 2012 & 24.5 & 13.8 & 44 & 25.1 & 13.5 & 41 & $7.3 \%$ & $-0.60[-6.41,5.21]$ & & \\
\hline Evcik 2002 & 15 & 3.5 & 28 & 30.4 & 6.5 & 26 & $9.2 \%$ & $-15.40[-18.21,-12.59]$ & $\rightarrow$ & \\
\hline Hartvigsen 2010 & 34 & 13.3 & 45 & 44 & 12.4 & 45 & $7.7 \%$ & $-10.00[-15.31,-4.69]$ & & \\
\hline Koldos Dogan 2008 & 38.3 & 30.4 & 19 & 55.4 & 30.4 & 18 & $1.9 \%$ & $-17.10[-36.70,2.50]$ & & \\
\hline McDonough 2013 & 38 & 25.3 & 39 & 41 & 26.3 & 17 & $2.9 \%$ & $-3.00[-17.81,11.81]$ & & \\
\hline Miller 2006 & 22.3 & 14.6 & 44 & 35 & 19.3 & 43 & $6.4 \%$ & $-12.70[-19.90,-5.50]$ & & \\
\hline Rooks 2007 & 41.1 & 20.3 & 51 & 50.7 & 23.9 & 50 & $5.5 \%$ & $-9.60[-18.26,-0.94]$ & & \\
\hline Valim 2003 & 25.7 & 17.4 & 32 & 31.7 & 21.5 & 28 & $4.8 \%$ & $-6.00[-15.99,3.99]$ & & \\
\hline Subtotal $(95 \% \mathrm{Cl})$ & & & 302 & & & 268 & $45.8 \%$ & $-9.31[-14.00,-4.61]$ & & \\
\hline \multicolumn{11}{|c|}{$\begin{array}{l}\text { Heterogeneity: } \operatorname{Tau}^{2}=27.47 ; \mathrm{Chi}^{2}=24.24, \mathrm{df}=7(\mathrm{P}=0.001) ; \mathrm{I}^{2}=71 \% \\
\text { Test for overall effect: } Z=3.88(P=0.0001)\end{array}$} \\
\hline \multicolumn{11}{|c|}{ 3.1.3 Long-term outcomes (>12 months) } \\
\hline Brosseau 2012 & 18.2 & 14.6 & 43 & 19.4 & 17.1 & 35 & $6.4 \%$ & $-1.20[-8.35,5.95]$ & & \\
\hline Ettinger 1997 & 34.4 & 10 & 144 & 40 & 8.2 & 149 & $9.6 \%$ & $-5.60[-7.70,-3.50]$ & $=$ & \\
\hline Schlenk 2011 & 27.8 & 19.4 & 13 & 31.7 & 15.1 & 13 & $3.4 \%$ & $-3.90[-17.26,9.46]$ & & \\
\hline Subtotal $(95 \% \mathrm{Cl})$ & & & 200 & & & 197 & $19.4 \%$ & $-5.22[-7.21,-3.23]$ & $\nabla$ & \\
\hline \multirow{2}{*}{\multicolumn{11}{|c|}{$\begin{array}{l}\text { Heterogeneity: } \operatorname{Tau}^{2}=0.00 ; \mathrm{Chi}^{2}=1.38, \mathrm{df}=2(\mathrm{P}=0.50) ; \mathrm{I}^{2}=0 \% \\
\text { Test for overall effect: } Z=5.14(\mathrm{P}<0.00001)\end{array}$}} \\
\hline & & & & & & & & & & \\
\hline \multirow{2}{*}{\multicolumn{9}{|c|}{$\begin{array}{l}\text { Total }(95 \% \text { Cl }) \quad 700 \quad 638100.0 \% \\
\text { Heterogeneity: } \text { Tau }^{2}=23.67 ; \mathrm{Chi}^{2}=62.84, \mathrm{df}=17(\mathrm{P}<0.00001) ; \mathrm{I}^{2}=73 \% \\
\text { Test for overall effect: } Z=4.71(\mathrm{P}<0.00001)\end{array}$}} & & \\
\hline & & & & & & & & & $-20-10$ & $\begin{array}{ll}0 & 1020 \\
0 & 20\end{array}$ \\
\hline
\end{tabular}

Test for subaroup differences: $\mathrm{Chi}^{2}=2.51, \mathrm{df}=2(\mathrm{P}=0.29), \mathrm{I}^{\mathrm{2}}=20.3 \%$ 


\section{Supplementary data: Appendix A. Medical Subject Heading (MeSH) terms used for identification of relevant studies}

4 Medline (via Ovid) search strategy:

\# Searches

1 motor activity.de.

2 walk\$.de.

lifestyle.mp. [mp=title, abstract, original title, name of substance word,

3 subject heading word, protocol supplementary concept, rare disease supplementary concept, unique identifier]

free-living activit\$.mp. [mp=title, abstract, original title, name of substance

4 word, subject heading word, protocol supplementary concept, rare disease supplementary concept, unique identifier]

accelerometer $\$ . m p$. [ $\mathrm{mp}=$ title, abstract, original title, name of substance

5 word, subject heading word, protocol supplementary concept, rare disease supplementary concept, unique identifier] pedometer $\$ . m p$. [mp=title, abstract, original title, name of substance word,

6 subject heading word, protocol supplementary concept, rare disease supplementary concept, unique identifier] activity monitor $\$ . m p$. [ $\mathrm{mp}=$ title, abstract, original title, name of substance

7 word, subject heading word, protocol supplementary concept, rare disease supplementary concept, unique identifier]

8 physical fitness.de.

9 exercise therapy.de.

10 aerobic $\$$.mp.

11 exercis\$.mp.

12 physical exercise.mp.

13 Musculoskeletal pain.mp.

14 Musculoskeletal diseases.mp.

15 dorsalgia.mp.

16 backache.mp.

17 back pain.mp.

18 Low back pain.de.

19 fibromyalgia.mp.

20 fibromyalgia syndrome.mp.

21 arthritis.mp.

22 osteoarthritis.mp.

23 rehabilitation.de.

24 morbidity.de.

25 mortality.de.

26 randomised controlled trial.mp.

27 controlled clinical trial.mp.

28 double blind method.mp.

29 single-blind method.mp.

301 or 2 or 3 or 4 or 5 or 6 or 7

318 or 9 or 10 or 11 or 12

3213 or 14

3315 or 16 or 17 or 18 or 19 or 20 or 21 or 22

3423 or 24 or 25

3526 or 27 or 28 or 29

$36 \quad 30$ and 31

$37 \quad 32$ and 36

$38 \quad 33$ and 36 
$39 \quad 30$ and 34

$40 \quad 33$ and 35 and 36

4133 or 35 or 36

4230 or 33

43 limit 42 to $y r=" 1980-C u r r e n t "$

4430 or 32

45 limit 44 to $y r=" 1980$-Current"

$46 \quad 35$ and 43

$47 \quad 35$ and 45

$48 \quad 33$ and 35 and 36

49 limit 44 to $y r=" 1980-C u r r e n t "$

$50 \quad 31$ and 33

51 limit 50 to $y r=" 1980-C u r r e n t "$ 
Supplementary data: Appendix B. Quality assessment and adequacy of exercise intervention criteria for individual studies (studies included in the meta-analysis are highlighted in bold)

\begin{tabular}{|c|c|c|c|}
\hline Study & Internal validity & $\begin{array}{l}\text { External } \\
\text { validity }\end{array}$ & $\begin{array}{l}\text { ACSM criteria } \\
\text { met }\end{array}$ \\
\hline Bautch et al, 2000 (27) & Poor & Fair & $1,3,4,5$ \\
\hline Bautch et al, 1997 (29) & Fair & Fair & $1,3,4,5$ \\
\hline Bircan et al, 2008 (44) & Fair & Fair & $1,2,3,4,5$ \\
\hline Brosseau et al, 2012 (36) & Fair & Good & $1,2,3,4,5$ \\
\hline Dias et al, 2003 (31) & Poor & Fair & $1,3,4,5$ \\
\hline Ettinger et al, 1997 (37) & Good & Fair & $1,2,3,4,5$ \\
\hline Evcik et al, 2002 (38) & Fair & Good & $1,4,5$ \\
\hline Ferrell et al, 1997 (52) & Fair & Fair & $1,2,4,5$ \\
\hline Hartvigsen et al, 2010 (48) & Good & Fair & $1,3,4,5$ \\
\hline Hiyama et al, 2012 (28) & Poor & Fair & $4 \quad 3$ \\
\hline Holtgrafe et al, 2007 (34) & Fair & Fair & $1,2,4,5$ \\
\hline $\begin{array}{l}\text { Koldas Dogan et al, } 2008 \\
\text { (49) }\end{array}$ & Fair & Fair & $1,2,3,4,5$ \\
\hline Kovar et al, 1992 (39) & Fair & Fair & $1,3,4,5$ \\
\hline Lemstra et al, 2005 (33) & Good & Good & $1,2,4,5$ \\
\hline Martin et al, 1996 (35) & Fair & Fair & $1,2,3,4,5$ \\
\hline $\begin{array}{l}\text { McDonough et al, } 2013 \\
\text { (51) }\end{array}$ & Good & Good & $1,4,5$ \\
\hline Messier et al, 2004 (40) & Fair & Fair & $1,2,3,4,5$ \\
\hline Meyer et al, $2000(30)$ & Poor & Fair & $1,4,5$ \\
\hline Miller et al, 2006 (41) & Fair & Fair & $1,2,3,4,5$ \\
\hline Nichols et al, 1994 (45) & Fair & Fair & $1,2,3,4,5$ \\
\hline $\begin{array}{l}\text { Rasmussen-Barr et al, } \\
2009 \text { (32) }\end{array}$ & Good & Good & $1,4,5$ \\
\hline $\begin{array}{l}\text { Rooks et al, } 2007 \text { (47) } \\
\text { Schlenk et al, } 2011 \text { (42) }\end{array}$ & $\begin{array}{l}\text { Good } \\
\text { Fair }\end{array}$ & $\begin{array}{l}\text { Good } \\
\text { Good }\end{array}$ & $\begin{array}{l}1,3,4,5 \\
4,5\end{array}$ \\
\hline $\begin{array}{l}\text { Shnayderman et al, } 2012 \\
(50)\end{array}$ & Fair & Good & $1,2,3,4,5$ \\
\hline Talbot et al, 2003 (43) & Poor & Good & $1,4,5$ \\
\hline Valim et al, 2003 (46) & Fair & Fair & $1,2,3,4,5$ \\
\hline
\end{tabular}

Using the following guideline criteria, internal and external validity of individual studies were judged as "good" "fair" or "poor" based on the following guideline criteria:

For internal validity: (1) Initial assembly of comparable groups: For RCTs: Adequate randomization including concealment and whether potential confounders were distributed equally among groups. (2) Maintenance of comparable groups (includes attrition, crossovers, adherence, and contamination). (3) Important differential loss to follow-up or overall high loss to follow-up. (4) Measurements: equal, reliable, and valid (includes masking of outcome assessment). (5) Clear definition of interventions. (6) All important outcomes considered. (7) Analysis: Intention-to treat analysis used for RCTs.

For external validity: (1) Biologic plausibility. (2) Similarities of the populations studied and primary care patients (in terms of risk factor profile, demographics, ethnicity, gender, clinical presentation, and similar factors). (3) Similarities of the test or intervention studied to those that would be routinely available or feasible in typical practice. (4) Clinical or social 
environmental circumstances in the studies that could modify the results from those expected in a primary care setting.

American College of Sports Medicine (ACSM) criteria for assessment of the adequacy of exercise interventions in individual studies: (1) Frequency of exercise of at least three days per week or twice a week for deconditioned individuals. (2) Intensity of exercise sufficient to achieve equal to or greater than $40 \%$ of heart rate reserve (min-max: $40-85 \%$ ) or $64 \%$ of predicted maximum heart rate (min-max: 64-94\%). (3) Sessions of at least 20 minutes duration (min-max: 20-60 minutes), either as continuous exercise or spread intermittently throughout the day in blocks of 10 minutes or more. (4) A mode of aerobic exercise involving major muscle groups in rhythmic activities. (5) Intervention should last for a minimum of six weeks. 
1 Supplementary data: Appendix C. List of studies excluded from the systematic

2 review where walking was not considered to be the predominant component of the

3 intervention

4

5 Bendix, AF, Bendix T, Lund C, et al. Comparison of three intensive programs for chronic

6 low back pain patients: a prospective, randomized, observer-blinded study with one-year

7 follow-up. Scandinavian Journal of Rehabilitation Medicine, 1997;29(2):81-89

9 Buckelew SP, Conway R, Parker $\mathrm{J}$ et al. Biofeedback/relaxation training and exercise 10 interventions for fibromyalgia: a prospective trial. Arthritis Care and Research, 11(3):19611209

12

13 Burckhardt CS, Mannerkorpi K, Hedenberg L. A randomized, controlled clinical trial of 14 education and physical training for women with fibromyalgia. Journal of Rheumatology, 15 1994;21(4):714-720

16 Chatzitheodorou D, Kabitsis C, Malliou P. et al. A pilot study of the effects of high-intensity 17 aerobic exercise versus passive interventions on pain, disability, psychological strain, and 18 serum cortisol concentrations in people with chronic low back pain. Physical Therapy, $19 \quad 2007 ; 87(3): 304-312$

20 Gowans SE, Dehueck A, Voss S et al. A randomized, controlled trial of exercise and 21 education for individuals with fibromyalgia. Arthritis Care and Research, 1999;12(2):120$22 \quad 128$

23 Gowans SE, Dehueck A, Voss S et al. Effect of a randomized, controlled trial of exercise

24 on mood and physical function in individuals with fibromyalgia. Arthritis and Rheumatism, $25 \quad 2001 ; 45(6): 519-529$

26 Martin K, Fontaine KR, Nicklas BJ, et al. Weight loss and exercise walking reduce pain and 27 improve physical functioning in overweight postmenopausal women with knee 28 osteoarthritis. Journal of Clinical Rheumatology, 2001;7(4):219-223

29 McCain GA, BELL DA, MAI FM ET AL. A controlled study of the effects of a supervised 30 cardiovascular fitness training program on the manifestations of primary fibromyalgia.

31 Arthritis and Rheumatism, 1988;31(9):1135-1141 
32 Meiworm I, Jakob E, Walker UA et al. Patients with fibromyalgia benefit from aerobic

33 endurance exercise. Clinical Rheumatology, 2000;19(4):253-257

34

35 Mengshoel, AM, Komnaes HB, Førre O. The effects of 20 weeks of physical fitness training 36 in female patients with fibromyalgia. Clinical and Experimental Rheumatology, 37 1992;10(4):345-349

39 Mirovsky Y, Grober A, Blankstein A. et al. The effect of ambulatory lumbar traction

40 combined with treadmill on patients with chronic low back pain. Journal of Back and

41 Musculoskeletal Rehabilitation, 2006;19(2-3):73-78

42 Richards SC, Scott DL. Prescribed exercise in people with fibromyalgia: parallel group

43 randomised controlled trial. British Medical Journal, 2002;27;325(7357):185

44 Saltska E, Jentoft R, Grimstvedt AK. et al. Effects of Pool-Based and Land-Based Aerobic 45 Exercise on Women With Fibromyalgia/Chronic Widespread Muscle Pain. Arthritis Care 46 and Research, 2001;45:42-47

47 Sculco AD, Paup DC, Fernhall B. et al. Effects of aerobic exercise on low back pain 48 patients in treatment. Spine Journal, 2001;1(2):95-101

49 Schachter, Cl, Busch AJ, Peloso PM. et al. Effects of short versus long bouts of aerobic 50 exercise in sedentary women with fibromyalgia: a randomized controlled trial. Physical 51 Therapy, 2003;83(4):340-358

52 Sjogren T, Long N, Storay I. et al. Group hydrotherapy versus group land-based treatment

53 for chronic low back pain. Physiotherapy Research International, 1997;2(4):212-222

54 Thorstensson CA, Roos EM, Petersson IF et al. Six-week high-intensity exercise program 55 for middle-aged patients with knee osteoarthritis: a randomized controlled trial 56 [ISRCTN20244858]. BMC Musculoskeletal Disorders, 2005;6:27

57 Tritilanunt T, Wajanavisit $\mathrm{W}$. The efficacy of an aerobic exercise and health education 58 program for treatment of chronic low back pain. Journal of the Medical Association of

59 Thailand, 2001;84:S2:S528-533

60 Wigers SH, Stiles TC, Vogel PA. et al. Effects of aerobic exercise versus stress 61 management treatment in fibromyalgia. A 4.5 year prospective study. Scandinavian 62 Journal of Rheumatology, 1996;25(2):77-86 
63 Yip YB, Sit JW, Gung KK et al. Effects of a self-management arthritis programme with an

64 added exercise component for osteoarthritic knee: randomized controlled trial. Journal of

65 Advanced Nursing, 2007;59(1):20-28

66

67 Chan CW, Mok NW, Yeung EW. Aerobic exercise training in addition to conventional

68 physiotherapy for chronic low back pain: a randomized controlled trial. Archives of Physical

69 Medicine and Rehabilitation, 2011,92(10):1681-5

70

71 Rantonen J. Luoto S. Vehtari A. et al. The effectiveness of two active interventions

72 compared to self-care advice in employees with non-acute low back symptoms: a

73 randomised, controlled trial with a 4-year follow-up in the occupational health setting.

74 Occupational \& Environmental Medicine, 2012;69(1):12-20

75

76 Sanudo B. Carrasco L. de Hoyo M. et al. Effects of exercise training and detraining in

77 patients with fibromyalgia syndrome: a 3-yr longitudinal study. American Journal of

78 Physical Medicine \& Rehabilitation, 2012;91(7):561-9

79

80 Hooten WM. Qu W. Townsend CO. et al. Effects of strength vs aerobic exercise on pain

81 severity in adults with fibromyalgia: a randomized equivalence trial. Pain, 2012;153(4):915-

82 23. .

83

84 Jensen RK. Leboeuf-Yde C. Wedderkopp N. et al. Rest versus exercise as treatment for 85 patients with low back pain and Modic changes. A randomized controlled clinical trial. BMC

86 Medicine, 2012;10:22

87

88 Hurley MV. Walsh NE. Mitchell H. et al. Long-term outcomes and costs of an integrated

89 rehabilitation program for chronic knee pain: a pragmatic, cluster randomized, controlled

90 trial. Arthritis care \& research, 2012;64(2):238-47

91

92 